\title{
Respect for Human Dignity in Caring for Patients with Cancer in Ilam, Perspectives of Patients and Nurses
}

\section{Milad Borji', Seyyed Rahmatollah Mousavi Moghadam², Mehdi Meymizade ${ }^{3}$}

${ }^{1}$ Department of Nursing, Faculty of Nursing and Midwifery, Ilam University of Medical Science, Ilam, Iran. ${ }^{2}$ Department of Islamic Education, Ilam University of Medical Sciences, Ilam, Iran.. ${ }^{3}$ Student Research Committee, Ilam University of Medical Sciences, Ilam, Iran.

\begin{abstract}
Objectives: Human dignity is one of the most important characteristics and ethical concerns in nursing care. This study was conducted with the aim of evaluating respect for human dignity in care for patients with cancer from both patients' and nurses' perspectives. Methods: In this cross-sectional descriptive study, 150 patients with cancer and 150 healthcare nurses were selected through convenience sampling. Data was collected from patients and nurses using a human dignity questionnaire about patient care; the validity and reliability of the questionnaire had been confirmed by previous studies. Data analysis was done using SPSS 20 software to carry out a statistical-descriptive test (mean and standard deviation) and statistical-inferential tests (t-test and one-way ANOVA). Results: According to the findings, for both patients and nurses, human dignity is very important in care for patients with cancer. Results also indicated that nurses consider respect for human dignity in patients with cancer to be at a desirable level, while from patients' perspective, it is low. Conclusions: Due to patients' feeling that respect for human dignity is low in care for patients with cancer, it is necessary to implement appropriate nursing interventions to increase human dignity in care for patients with cancer.
\end{abstract}

Keywords: Human dignity- cancer- nurse

Asian Pac J Cancer Biol, 1 (2), 43-46

\section{Introduction}

Human dignity is an important characteristic and among the main ethical concerns in nursing care [1]. Human dignity is defined as respect for basic human rights [2]. Indeed, dignity is related to any individual's existence and nature and this is taken into account in the healthcare system [3]. According to the concept of human dignity, all human beings are created free and equal in terms of dignity and rights $[2,4,5]$.

Attention to patient dignity has a long history in medical disciplines; it perhaps dates back to Socrates' philosophy and his emphasis on respect for patient dignity. This concept is also seen in works by Plato and Aristotle in the period before Islam. However, Islam not only emphasizes the idea of patient dignity, but also pays special attention to its different aspects such as the mutual rights of patient and physician, and patient and community [6]; human dignity is a concept that is emphasized in the Holy Quran, the various verses of which not only
Submission Date: 03/12/2016 Acceptance Date: 05/25/2016

emphasize the human dignity granted to men by God, but also stipulate human dignity as the vicegerent of Allah [7]

To provide appropriate nursing care, nurses need to maintain open and honest communication with patients, respect patients' personal and professional values, and be sensitive to differences in people [6]. According to the results of various studies, medical and nursing staff have low awareness of the importance of respect for patients' privacy and dignity and have differing understanding of these concepts. Therefore, healthcare service providers should provide for the promotion and preservation of dignity in clinical centers by identifying factors affecting patient dignity $[8,9]$.

Cancer is a disease that threatens human dignity [10]. Cancer is one of the most significant challenges to the health system and between 1990 and 2010 the cause of eight million deaths globally [11]; dignity-related problems, lower quality of life, and higher levels of depression are reported in patients with cancer [10]. Cancer creates anxiety in patients and is closely related to performance,

Corresponding Author:

Dr. Seyyed Rahmatollah Mousavi Moghadam

Department of Islamic Education, Ilam University of Medical Sciences, Ilam, Iran.

Email: prof.m1344@gmail.com 
and physical and psychological problems [12-13].

There should be more emphasis on technical and medical care such as surgery, radiotherapy, gene therapy, and chemotherapy in care for patients with cancer; and nursing care should be based on the patient's personal characteristics and needs, so that care is determined according to demographic characteristics, interests, and social and cultural characteristics, as well as the specific physiology of the disease [14]. According to the results of previous studies, patient dignity has a close relationship with factors such as respect, privacy, independence, and support [15-17]. Based on the findings of a literature review, there is little information regarding respect for human dignity in care for patients with cancer; this study was therefore conducted with the aim of investigating respect for human dignity in care for patients with cancer, from both patients' and nurses' perspectives, in 2017.

\section{Materials and Methods}

This cross-sectional descriptive study was conducted in Ilam City in 2017. Using previous studies as a reference [7], 150 patients and 150 nurses were selected by convenience sampling. The population of this study consisted of patients with cancer admitted to hospitals in Ilam City and the nurses involved in their care. An inclusion criterion for nurses was having a bachelor's degree or higher. Inclusion criteria for patients were lack of evidence of mental health problems in responding to questions, consciousness, being a minimum of 6 months post cancer diagnosis, and admission to a hospital in Ilam City. Both nurses and patients provided informed consent for participation in the study.

Demographics and data on human dignity in patient care was obtained from both nurses and patients using a questionnaire comprising of three sections. The first section of the questionnaire investigated the importance of different aspects of care affecting human dignity in patient recovery. It consisted of 13 care-related items that affect human dignity and investigated the importance of different aspects of care relating to respect for human dignity using a scale, with 1 representing lowest importance and 10 highest importance. The second section of the questionnaire measured compliance with different aspects of care relating to respect for human dignity according to 9 items considering privacy, healthcare, and measures necessary to respecting patients' human dignity based on a scale 1 to 10 , with 1 representing lowest importance and 10 highest importance. The first and second sections of this questionnaire were similar for both nurses and patients participating in this study, but the third section of questionnaire studied only nurses and included items measuring the help given by hospital staff to nurses in respecting patients' human dignity whilst providing healthcare. This section measured 7 ways of facilitating nurses' respectful care; nurses were required to provide Yes or No responses to questions. It should be noted that at the end of all sections of the questionnaire, the participants were asked to comment generally on the rate of respect for human dignity in patients with cancer. Reliability and validity of this questionnaire were evaluated in a study by Sabeghi et al. The validity of the questionnaire considered content type, and its reliability was 0.89 for nurses and 0.85 for elderly patients according to Cronbach's alpha coefficient [7]. Since there were different patients in this study, the reliability of the questionnaire was recalculated and it was, according to Cronbach's alpha coefficient, 0.92 for nurses and for 0.87 for patients.

The researcher collected data after gaining permission from the Council on Research Ethics at Ilam University of Medical Sciences with project code and code of ethics in research of Ethical considerations of this research included obtaining informed consent from patients and nurses who participated in the study, information on research objectives for subjects, non-imposed costs on patients, and confidentiality of information obtained during the research. Data analysis was done using statistical SPSS 20 software and statistical descriptive tests (mean and standard deviation) and statistical inferential tests (t-test and one-way ANOVA).

\section{Results}

the finding of the study showed that more nurse is female $109(72.7 \%)$ and $41(27.3)$ of nurse is male. more nurse $141(94 \%)$ is Bachelor and $9(6 \%)$ is master of nursing. Mean and SD age of nurse is 38.73(10.21). About patoin with cancer result showed that more nurse is female $109(72.7 \%)$ and $41(27.3)$ of nurse is male. more nurse $141(94 \%)$ is Bachelor and $9(6 \%)$ is master of nursing. Mean and SD age of nurse is 38.73(10.21).

According to the findings of this table 1 , human dignity

Table 1. Nurses and Patients' Views on the Importance of Various Aspects of Care Affecting Human Dignity in Patient Recovery

\begin{tabular}{lcc}
\hline & \multicolumn{2}{c}{ Group } \\
Items & $\begin{array}{c}\text { Patients with cancer } \\
\text { M(SD) }\end{array}$ & $\begin{array}{c}\text { Nurses } \\
\text { M(SD) }\end{array}$ \\
\hline $\begin{array}{l}\text { 1. Using healthcare measures (e.g. } \\
\text { medication, etc.) }\end{array}$ & $8.64(1.38)$ & $7.56(1.04)$ \\
$\begin{array}{l}\text { 2. Listening to patients } \\
\text { 3. Caring based on patient need }\end{array}$ & $9.11(.72)$ & $6.99(.93)$ \\
$\begin{array}{l}\text { 4. Getting meals to patients at the } \\
\text { right time }\end{array}$ & $8.17(1.38)$ & $7.32(1.53)$ \\
$\begin{array}{l}\text { 5. Helping patients with eating, } \\
\text { dressing, etc., if necessary }\end{array}$ & $7.15(1.73)$ & $6.56(1.24)$ \\
$\begin{array}{l}\text { 6. Providing appropriate clothing } \\
\text { during hospital stays }\end{array}$ & $5.86(1.15)$ & $7.30(1.36)$ \\
$\begin{array}{l}\text { 7. Ensuring a safe patient environ- } \\
\text { ment }\end{array}$ & $7.23(1.51)$ & $7.43(1.07)$ \\
$\begin{array}{l}\text { 8. Keeping patients' private infor- } \\
\text { mation confidential }\end{array}$ & $8.10(1.46)$ & $7.13(1.43)$ \\
$\begin{array}{l}\text { 9. Establishing professional com- } \\
\text { munication and collaboration with } \\
\text { patients and their families }\end{array}$ & $9.12(.94)$ & $6.77(1.77)$ \\
$\begin{array}{l}\text { 10. Providing enough information } \\
\text { regarding patient care plans }\end{array}$ & $7.39(2.20)$ & $7.02(1.35)$ \\
$\begin{array}{l}\text { 11. Involving patients in their } \\
\text { discharge plans }\end{array}$ & $6.01(1.44)$ & $7.72(1.26)$ \\
\hline
\end{tabular}


Table 2. Nurses and Patients' Views on Respect for Various Aspects of Care Affecting Human Dignity in Patient Recovery

\begin{tabular}{|c|c|c|}
\hline \multirow{3}{*}{ Items } & \multicolumn{2}{|l|}{ Group } \\
\hline & Patients with cancer & Nurses \\
\hline & $\mathrm{M}(\mathrm{SD})$ & $\mathrm{M}(\mathrm{SD})$ \\
\hline 1. Respecting privacy & $8.03(.87)$ & $8.73(1.09)$ \\
\hline $\begin{array}{l}\text { 2. Allocating sufficient time to } \\
\text { patients for discussion }\end{array}$ & $6.23(1.07)$ & $8.25(1.19)$ \\
\hline $\begin{array}{l}\text { 3. Respecting patient demands and } \\
\text { needs in care provision }\end{array}$ & $5.41(1.11)$ & $7.23(1.35)$ \\
\hline $\begin{array}{l}\text { 4. Providing care in a timely } \\
\text { manner and in accordance with } \\
\text { professional standards }\end{array}$ & $6.13(1.06)$ & 7.61(1.14) \\
\hline $\begin{array}{l}\text { 5. Providing appropriate space for } \\
\text { patients' eating and dressing needs }\end{array}$ & $4.22(2.49)$ & $6.27(1.27)$ \\
\hline $\begin{array}{l}\text { 6. Observing the compliance plan } \\
\text { during patient care }\end{array}$ & $4.33(1.43)$ & $7.55(1.10)$ \\
\hline $\begin{array}{l}\text { 7. Providing sufficient informa- } \\
\text { tion to patients during care and } \\
\text { treatment }\end{array}$ & $3.14(1.14)$ & $7.97(.95)$ \\
\hline $\begin{array}{l}\text { 8. Providing the right to choose to } \\
\text { patients during care and treatment }\end{array}$ & $4.13(1.90)$ & $8.04(.87)$ \\
\hline $\begin{array}{l}\text { 9. Ensuring that patients have } \\
\text { appropriate clothing in during } \\
\text { hospital visits/stays }\end{array}$ & $7.54(1.96)$ & $8.01(.94)$ \\
\hline
\end{tabular}

Table 3. Comparing the Mean and Standard Deviation of Nurses' and Patients' Views on the Importance of and Respect for Human Dignity in Hospitalized Patients

\begin{tabular}{lccc}
\hline Variable & Patients with cancer & Nurses & $\mathrm{P} \& \mathrm{~F}$ \\
& $\mathrm{M}(\mathrm{SD})$ & $\mathrm{M}(\mathrm{SD})$ & \\
\hline $\begin{array}{l}\text { Importance of human } \\
\text { dignity }\end{array}$ & $84.40(4.64)$ & $79.07(4.40)$ & $\mathrm{P}<0.61$ \\
$\begin{array}{l}\text { Respect for human } \\
\text { dignity }\end{array}$ & $49.16(4.39)$ & $69.67(3.67)$ & $\mathrm{P}<0.007$ \\
$\mathrm{~F}=7.51$ \\
\hline
\end{tabular}

is very important to both patients and nurses in care for patients with cancer (Table1). Findings from the second section of the questionnaire indicate that respect for human dignity in patients with cancer was desirable from nurses' perspective, but weak from patients' perspective (Table2).

According to the findings of this table 3 no Significant statistical relationship between Importance of human dignity in nurse and Patients with cancer $(\mathrm{P}<0.61)$. but is Significant statistical relationship between Respect for human dignity in nurse and Patients with cancer $(\mathrm{P}<0.007)$. (table3)

\section{Discussion}

According to the findings of this study, human dignity is very important to both patients and nurses in care for patients with cancer. According to research carried out among hospitalized elderly patients by Sabeghi et al [7], human dignity is very important in hospitalized elderly patients' care, from both patients and nurses' perspective, and this is consistent with the results of this research. Patient dignity has been considered as a right in codes of ethics, and thus its preservation and improvement have been considered as fundamental to nursing roles [18].

The findings from the first section of the questionnaire on the importance of respect for human dignity in patients with cancer indicate that the nurses' mean scores were higher than the patients and this is consistent with the results of research by Sabeghi et al [7] among hospitalized elderly patients and nurses, but it is inconsistent with the results of Ebrahimi et al.'s research [15]which found that patients' mean scores were higher than nurses'.

Findings from the second section of the questionnaire indicate that respect for human dignity in patients with cancer was desirable from nurses' perspective, but weak from patients' perspective. Various studies have investigated respect for dignity in patients with cancer and they are consistent with the results of this research. For instance, Shah-Hosseini et al. studied human dignity in women with breast cancer. In this research, the total mean of a dignity score was 1.94 out of 5 . Furthermore, the patients' total mean was 2.40 in dimensions of symptoms of tension, 1.87 in existential tension, 1.71 in dependence and social support [9]; this was consistent with the results of this study. However, according to the results of research conducted by Chochinov et al. among patients with cancer, the loss of dignity constituted only 7.5 percent of the concerns of patients with cancer, and 54 percent of patients stated that there was not any threat to their dignity [19]. This is inconsistent with the results of this study, which reports insufficient respect for human dignity in patients with cancer from patients' perspectives.

Several studies have investigated patients' human dignity. For instance, patients' mean score of human dignity was equal to 3.79 out of 6 according to research by Azami et al. among patients with cardiovascular disease in Shahid Mostafa hospital in Ilam City [20]. Moravveji et al. studied the inherent and social dignity in patients with cardiovascular disease in Zanjan City. According to their findings, the patients' mean score of human dignity was 5 and their social dignity was 4 out of 6 [21]. According to research by Amininasab et al. among patients with cardiovascular disease, the score of human dignity was 81.39 out of 125 , indicating a threat to patients' dignity. This is consistent with the results of this research, which found low respect for human dignity in the treatment of patients with cancer.

In terms of the importance of various healthcare aspects that affect human dignity in patients, based on nurses' perspective, findings of this research indicate that the highest mean score was for listening to patients, while the lowest score was in providing information on patient healthcare programs. According to research by Sabeghi et al [7], the highest score belonged to safe patient environment, while the lowest score was related to patient participation in their discharge plan; this result was inconsistent with the current study. Different types of patient resulted in different results in the above-mentioned study and existing research.

Regarding the third section of this questionnaire, which was concerned with the provision of help to nurses by hospital officials, in order to maintain respect for 
patients' human dignity in care, results indicate that the highest mean score was for the possibility of reporting non-respected dignity in care to authorities without any fear, while the lowest score was for the design of the workplace in wards such that human dignity is specifically respected in care. In research conducted by Sabeghi et al. [7], the highest score belonged to the item of "Employing new staff and taking into account the importance of dignity-respecting care", while the lowest score belonged to the item of "Presence of personnel with good knowledge on the ward". This is inconsistent with the results of current study [7]. Different types of patient resulted in different findings for the above-mentioned study and the current research.

In conclusion according to the findings of this study, respect for human dignity from patients' perspective is low in care for patients with cancer, but from nurses' perspective, it is at a desirable level. Therefore, there should be appropriate nursing interventions to enhance human dignity in patients with cancer.

\section{Acknowledgements}

This study was approved by the Research Committee of Ilam University of Medical Sciences with project code of and the code of ethics of The researchers would like to thank Ilam University of Medical Sciences for financial and moral support, as well as the patients and nurses who participated in this study for their cooperation.

\section{References}

1. Lin YP, Watson R, Tsai YF. Dignity in care in the clinical setting: a narrative review. Nursing ethics. 2013;20(2):16877.

2. Lam K. Dignity. respect for dignity, and dignity conserving in palliative care. HKSPM Newsletter. . 2007;;3::30-5.

3. Matiti MR, Trorey GM. Patients' expectations of the maintenance of their dignity. Journal of clinical nursing. 2008;17(20):2709-17.

4. KNOEPFFLER N OMM. Human dignity: regulative principle and absolute value. . Journal de médecine légale, droit médical, victimologie, dommage corporel 2012;;55((12):):56-63.

5. Bagheri H YF, Ashktorab T, Zayeri F. . Evaluation Inherent Dignity and Its Related Factors in Heart Failure Patients. . Journal of Knowledge \& Health. 2015;;10((2):):56-62.

6. Sadeghi T DNN. Patients' dignity: patients' and nurses' perspectives. [Research] . Iranian Journal of Medical Ethics and History of Medicine 2009;;3((1):):9-20.

7. Sabeghi H NA, Zarei M, Tabar AK, Golbaf D. Respecting for human dignity in elders caring in perspective of nurses and elderly patients. . Medical Ethics Journal 2017;;9((32):):4570.

8. Matiti MR. Learning to promote patient dignity: an interprofessional approach. Nurse education in practice. 2015;15(2):108-10.

9. Shahhoseini S BF, Atashzadeh-Shoorideh F, Kavousi A. Assessment of Human Dignity in Women with Breast Cancer Undergoing Chemotherapy. . Medical Ethics Journal 2017;;11((39):):7-17.

10. Hall S, Davies JM, Gao W, Higginson IJ. Patterns of dignity- related distress at the end of life: a cross-sectional study of patients with advanced cancer and care home residents. Palliative medicine. 2014;28(9):1118-27.

11. Naderimagham S, Alipour S, Djalalinia S, Kasaeian A, Noori A, Rahimzadeh S, et al. National and sub-national burden of breast cancer in Iran; 1990-2013. Archives of Iranian medicine. 2014;17(12):794-9.

12. Carlson LE, Waller A, Mitchell AJ. Screening for distress and unmet needs in patients with cancer: review and recommendations. Journal of clinical oncology : official journal of the American Society of Clinical Oncology. 2012;30(11):1160-77.

13. Smith EML PH, Cirrincione C, Fleishman S, Paskett ED, Ahles T, et al. . Effect of duloxetine on pain, function, and quality of life among patients with chemotherapy-induced painful peripheral neuropathy: a randomized clinical trial. Jama. 2013; . 1359-67. p.

14. Rahnama M FKM, Seyed Bagher Madah S, Ahmadi F. Cancer patients' perception of spiritual care. Iranian Journal of Medical Ethics and History of Medicine [Research] 2012;;5((3):):64-80.

15. Ebrahimi H TC, Mohammadi E, Valizadeh S. Patients' perception of dignity in Iranian healthcare settings: a qualitative content analysis. . Journal of medical ethics 2012;;38((12):):723-8.

16. Gallagher A, Li S, Wainwright P, Jones IR, Lee D. Dignity in the care of older people - a review of the theoretical and empirical literature. BMC nursing. 2008;7:11.

17. Cairns D, Williams V, Victor C, Richards S, Le May A, Martin W, et al. The meaning and importance of dignified care: findings from a survey of health and social care professionals. BMC geriatrics. 2013;13:28.

18. Bagheri H YF, Ashktorab T. Patient dignity and related factors: a qualitative meta-synthesis study. . Journal of Knowledge \& Health 2011;;6((1):):49-56.

19. Chochinov HM, Hack T, Hassard T, Kristjanson LJ, McClement S, Harlos M. Dignity in the terminally ill: a cross-sectional, cohort study. Lancet (London, England). 2002;360(9350):2026-30.

20. Azami M MK, Tavan H, Borji M. Assessing Human Dignity of the Patients with Cardiovascular Diseases at Shahid Mostafa Khomeini Hospital in the city of Ilam. Medical Ethics Journal 2016;;10((37):):61-8.

21. Moraveji M YF, Bagheri H. . Dignity of heart failure patients referred to Zanjan hospitals. . Journal of Health Promotion Management [Research] 2015;;4((4):):75-83.

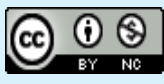

This work is licensed under a Creative Commons AttributionNonCommercial 4.0 International License. 